\title{
Micromilling of thin ribs with high aspect ratios
}

\author{
P Li ${ }^{1}$, D Zdebski ${ }^{2}$, H H Langen ${ }^{1}$, A M Hoogstrate ${ }^{3}$, J A J Oosterling ${ }^{3}$, \\ R H Munnig Schmidt ${ }^{1}$ and D M Allen ${ }^{2}$ \\ ${ }^{1}$ Department of Precision and Microsystems Engineering, Delft University of Technology, Mekelweg 2, \\ 2628CD, Delft, the Netherlands \\ ${ }^{2}$ Precision Engineering Centre, Cranfield University, Cranfield, Bedfordshire MK43 0AL, UK \\ ${ }^{3}$ TNO Science and Industry, P O Box 6235, 5600HE, Eindhoven, the Netherlands \\ E-mail: p.li@tudelft.nl
}

Received 9 May 2010, in final form 15 August 2010

Published 8 October 2010

Online at stacks.iop.org/JMM/20/115013

\begin{abstract}
Micro features with high aspect ratios are one of the commonly encountered geometries found in micro products. In the literature, these structures are often used in demonstrator products machined by a micromilling process. In this paper, the challenges in micromilling thin ribs with high aspect ratios have been studied. Due to the scaling effect, micro-ribs have relatively low stiffness but high natural frequency. Therefore, on the one hand, average forces have to be controlled well to avoid structural bending or even damage, while on the other hand, micro features are unlikely to be excited by the dynamic forces. The characteristics of micromilling forces and their relationships to the machining parameters, namely, feed per tooth, depth of cut and width of cut, were studied theoretically by force models. In addition, the effects of different milling strategies (up-/down-milling) and tool paths on the quality of thin features have been investigated using FEM. The results allow measures to be taken to minimize the force effects and support the micro features during machining. The experimental results verify the theoretical studies. Thin ribs about $15 \mu \mathrm{m}$ wide and with an aspect ratio of more than 50 were machined with good form and surface quality.
\end{abstract}

(Some figures in this article are in colour only in the electronic version)

\section{Introduction}

Micro features with high aspect ratios (AR), such as micro poles, gear shafts, bars and ribs, are the most commonly reported examples that are machined by micromilling [1-8]. Applications of such geometries include micro structures on single products, EDM electrodes and micro moulds for injection moulding. In addition, high aspect ratio micro features are often used as a criterion to evaluate the capability of micromachining processes [3,9]. For example, it was observed in [9] that micromilling (by $\varnothing 0.1 \mathrm{~mm}$ endmills) is suitable for machining features with a width of $100 \mu \mathrm{m}$ and AR of 10-15.

The important factors that influence micromachining of micro features are (a) workpiece materials, (b) dimensions and geometry of the micro-features, (c) machine and cutting tools, (d) machining parameters and (e) tool paths. The effect of some of these factors on the quality of machining is well documented in the literature. Je et al [8] have studied the effects of (a) and (b) using FEM. It was reported that for higher strength materials, the deformation of micro features was smaller. They noted that smaller dimensions of thin features led to larger deformations. Their results indicated that material with high strength should be chosen as the workpiece material in order to machine micro features with high aspect ratios. In addition, the process forces have to be minimized when feasible.

For a given machining environment, when the properties of (a), (b) and (c) are known, the quality of the micromachining is predominantly influenced by (d) and (e). This paper focuses on the effects of machining parameters and the tool path.

The machining parameters primarily influence the forces in micromilling. These are the cutting speed $\left(v_{c}\right)$, depth of cut $\left(a_{p}\right)$, width of cut $\left(a_{e}\right)$ and feed per tooth $\left(f_{z}\right)$. Using aggressive machining parameters improves productivity. However, they normally produce high cutting forces, which cause bending 


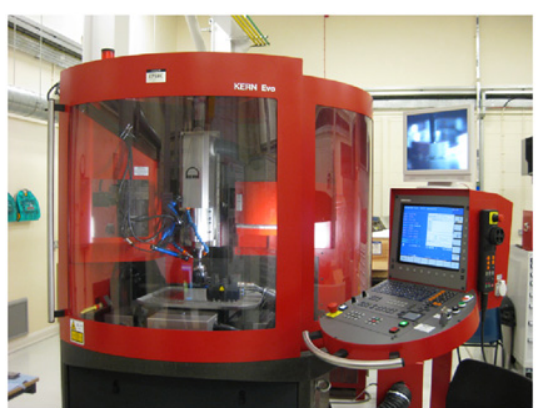

(a)

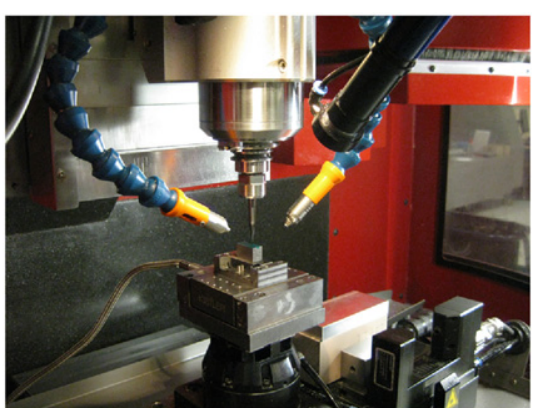

(b)

Figure 1. The experimental setup: (a) KERN EVO machine and (b) zoom-in of the machining area.

or damage to the micro parts and micro cutting tools. Conservative parameters lead to low forces which are safe. However, the cutting may fall in an unfavourable zone due to the minimum chip thickness effect [10-13]. This leads to a relatively longer machining time. In practice, the machining parameters are often determined on a trial-and-error basis [14]. In order to overcome this, Özel et al [14] proposed a modelbased method to determine the machining parameters. An analytical model was used to select feed per tooth to avoid the minimum chip thickness effect. A time domain simulation model was used to predict cutting forces, surface form and roughness. This method was verified by machining micro cavities and therefore bending of the micro features was not discussed.

Another issue that needs careful consideration is the choice of tool path for machining thin features. Dimov et al [15] called for new strategies in micromilling due to its unique characteristics. It was suggested that a strategy should be adaptively developed according to the specific geometry of the component. One design principle is to provide support to the feature during machining. Currently, constant level $Z$ is often used $[1,6,8]$ for micromachining of micro-features with high aspect ratios. Micro pins that are $20 \mu \mathrm{m}$ in diameter and having an aspect ratio of 35 were machined using this tool path in [8].

In this paper, the process of micromilling of thin ribs with high aspect ratios is studied. The objective is a fundamental understanding of the micromilling process with the aim of improving the reliability and quality of the end product. Towards this end, an adaptive procedure has been undertaken, involving real-time acquisition of the cutting forces, modelling of the observed forces using suitable machining parameters and subsequent design of tool paths. The effects of different milling strategies, such as up-/down-milling, and tool paths on the quality of thin features have been investigated using FEM. The theoretical developments were experimentally verified on a commercial Kern Evo micro machining centre.

\section{Characteristics of micromilling forces}

The Kern Evo machine is shown in figure 1. It contains a hybrid-bearing spindle that can rotate up to $50000 \mathrm{rpm}$. The Kern machine is equipped with high precision collet-type tool holders. The cutting tools used were two-flute TiAlN-coated ultra-fine grain tungsten carbide $\varnothing 0.5$ square endmills with straight corners. The tools were produced in one batch to avoid possible deviations in quality. To check for premature damage, each tool was visually inspected under a microscope. Workpieces were made of tool steels, AISI H11 with 54 HRC and Böhler M261 with 46 HRC. The workpiece was first ground to achieve good surface flatness.

To understand the cutting forces, a preliminary milling operation of slot cutting was performed. The cutting conditions were chosen according to the recommended cutting parameters by the tool supplier: depth of cut $\left(a_{p}\right) 0.02-$ $0.37 \mathrm{~mm}$, width of cut $\left(a_{e}\right) 0.02-0.5 \mathrm{~mm}$ and feed per tooth $\left(f_{z}\right)$ 0.005-0.009 mm, depending on the operation (e.g. side milling or slot milling). The cutting forces were measured by a dynamometer, the Kistler MiniDyn 9256C2.

The measured cutting forces are influenced by the presence of runout on the spindle. In order to reduce these effects, the static runout at the end of the tool shaft was measured before each experiment. This was achieved by using a high precision dial gauge and the runout was manually controlled to be smaller than $1 \mu \mathrm{m}$, by adjusting the tool clamp. The dynamic runout was checked by visual inspection of the force signal.

In micromilling, the cutting forces are characterized by a static component and a dynamic component, very similar to the case of conventional milling. The static force causes bending of the micro cutting tool or the micro feature during machining. The dynamic component, on the other hand, influences the texture of the machined surface [16]. The objective is to understand the bending phenomenon within micro-ribs and therefore the focus is on the study of average force.

In figure 2, the various facets of the measured force signals are examined in detail in the subfigures. The measured signals are typical of a micromilling process and allow a deeper insight into the phenomenon. The static and dynamics components can be clearly seen in figure 2(a), which shows the measured signal during one revolution of the spindle. The two crests are a result of the two flutes of the cutting tool. The unequal magnitudes of the crests indicate the presence of dynamic runout at the tool tip. The dynamic runout is, in general, attributed to unbalanced mass, eccentricity in the spindle, tool clamping and tool geometry. An elementary analysis using the frequency spectrum of the force signals clearly shows a strong component of the spindle frequency. 


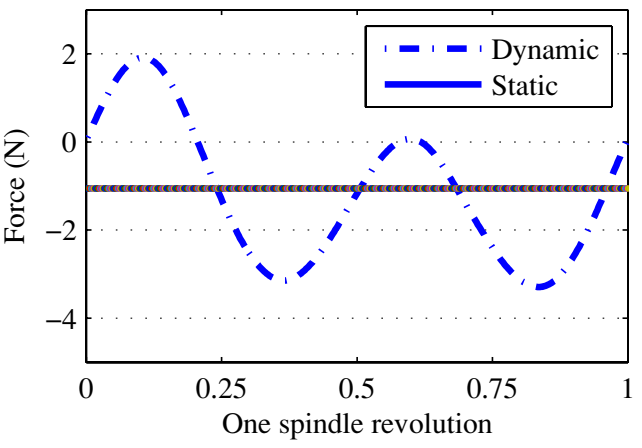

(a)

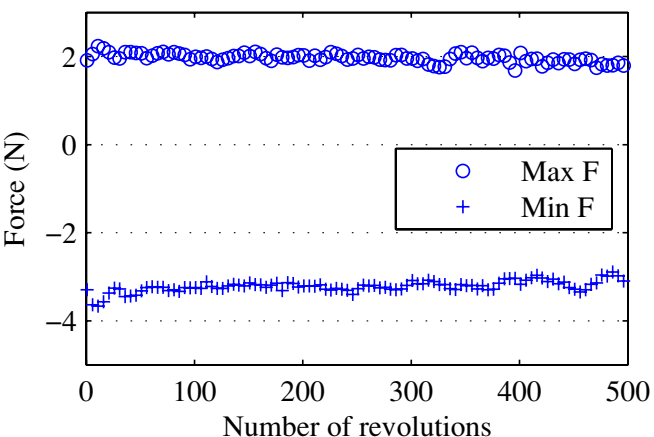

(b)

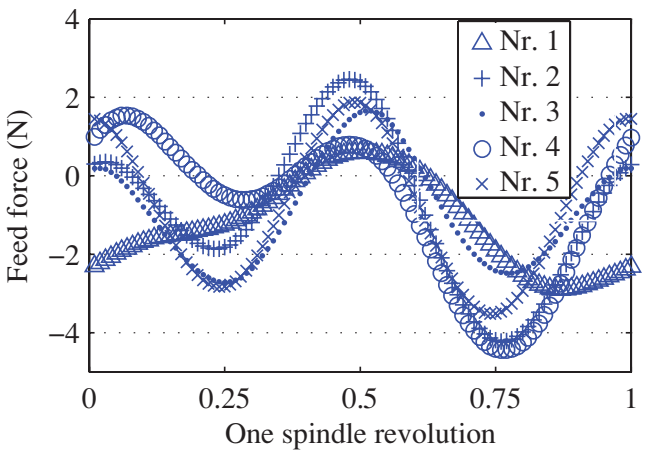

(c)

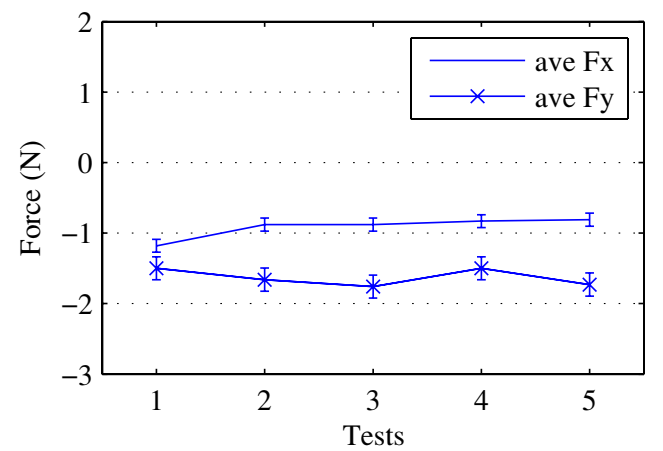

(d)

Figure 2. Example of micromilling forces. The low pass filter $(2000 \mathrm{~Hz})$ was applied to maintain components due to cutting. Cutting conditions: $\varnothing 0.5 \mathrm{~mm}$ endmills, workpiece AISI H11 with $54 \mathrm{HRC}, v_{c} 47.1 \mathrm{~m} \mathrm{~min}^{-1}, f_{z} 0.007 \mathrm{~mm}, a_{p} 0.07 \mathrm{~mm}$ and slot milling. $F_{x}$ is force measured in the feed direction; $F_{y}$ is force in cross-feed direction. (a) A typical force plot $\left(F_{x}\right)$ in one spindle revolution, $(b)$ the fluctuation of maximum and minimum forces in 500 spindle revolutions, $(c)$ comparison of the dynamic forces (in one spindle revolution) measured in five tests and $(d)$ the comparison of average forces in five tests. In $(c)$ and $(d)$, the same experiment was repeated five times with five new micro endmills under the same nominal cutting conditions.
The cutting forces during a typical micromilling operation often fluctuate. The observed maximum and minimum cutting forces during each revolution fluctuate as seen in figure $2(b)$. For a sample of 500 revolutions, the forces vary within a band of about $\pm 0.27 \mathrm{~N}(10-15 \%$ of the average value). The fluctuations make it extremely difficult to model the dynamic forces accurately. The inhomogeneity of the workpiece material, changes in cutting tool geometry due to wear and vibrations are primarily responsible for the force fluctuations.

In order to verify the repeatability of the cutting forces, the measurements were sampled over five experiments under identical conditions. The measured forces during one revolution of the spindle are shown in figure 2(c) for all the experiments. These forces suggest lack of reproducibility of the dynamics under similar cutting conditions. This is because the dynamic micromilling forces are influenced significantly by the process runout. Runout is influenced by many factors, such as micro cutting tool, tool holder and spindle runout. Since there is no good accurate method to measure runout online, it was not possible to improve the repeatability of the dynamic forces. However, when the average forces for each experiment are compared in figure $2(d)$, it can be observed that the variations are acceptable. This is because the cutting force is proportional to the removal chip volume. Since all these experiments were conducted under the same nominal cutting conditions, they showed similar average force. In addition, the average has been calculated over a large number of spindle revolutions, which reduced the fluctuation of the forces. This allows the assumption of average force repeatability and they can therefore be used for modelling purposes.

\section{Relationship between average micromilling forces and machining parameters}

\subsection{Average force model}

The cutting forces in micromilling were modelled using the mechanistic force model developed by Altintas [17]. This model was primarily developed for macro-scale milling. However, the results indicate its overall utility in modelling average forces that arise in micromilling. A short introduction to the basic principles of this model is given here. The interested reader is referred to [17] for the theoretical details of the model.

The coordinate system for the force model is shown in figure 3. The relationship between the elemental forces (tangential force $\mathrm{d} F_{t}$ and radial force $\mathrm{d} F_{r}$ ) and process parameters (instantaneous chip thickness $h$ and elemental depth of cut $\mathrm{d} z$ ) at a rotational angle $\theta$ can be expressed as

$$
\begin{gathered}
\mathrm{d} F_{t}(\theta)=\left(K_{t c} h(\theta)+K_{t e}\right) \mathrm{d} z, \\
d F_{r}(\theta)=\left(K_{r c} h(\theta)+K_{r e}\right) \mathrm{d} z, \\
h(\theta)=f_{z} \sin (\theta),
\end{gathered}
$$

where $K_{t c}$ and $K_{r c}$ are the cutting force coefficients, $K_{t e}$ and $K_{r e}$ are the edge force coefficients to take into account the ploughing effect, $f_{z}$ is feed per tooth.

The elemental forces can be resolved into the $X$ - and $Y$ directions, and integrated along the axial depth of cut and 
Table 1.Validation of Altintas' force model in predicting average forces in micromilling.

\begin{tabular}{lllllllc}
\hline Test & $a_{e}(\mathrm{~mm})$ & $a_{p}(\mathrm{~mm})$ & $f_{z}(\mu \mathrm{m})$ & & Measurement $(\mathrm{N})$ & Prediction $(\mathrm{N})$ & Error $(\%)$ \\
\hline 1 & 0.5 & 0.05 & 5 & Ave $F_{x}$ & -1.15 & -1.23 & 7.2 \\
& & & & Ave $F_{y}$ & -0.79 & -0.74 & 6.8 \\
2 & 0.5 & 0.03 & 9 & Ave $F_{x}$ & -1.50 & -1.34 & 10.4 \\
& \multirow{2}{*}{0.5} & \multirow{2}{*}{0.07} & \multirow{2}{*}{7} & Ave $F_{y}$ & -0.87 & -0.79 & 8.7 \\
& \multirow{2}{*}{0.5} & Ave $F_{x}$ & -2.19 & -2.05 & 6.6 \\
4 & \multirow{2}{*}{0.5} & \multirow{2}{*}{0.09} & Ave $F_{y}$ & -1.64 & -1.46 & 10.9 \\
& & & & Ave $F_{x}$ & -1.79 & -1.82 & 1.5 \\
& & & Ave $F_{y}$ & -1.38 & -1.47 & 5.9 \\
\hline
\end{tabular}

Note: only slot milling was conducted to avoid uncertainty in the width of cut due to runout.

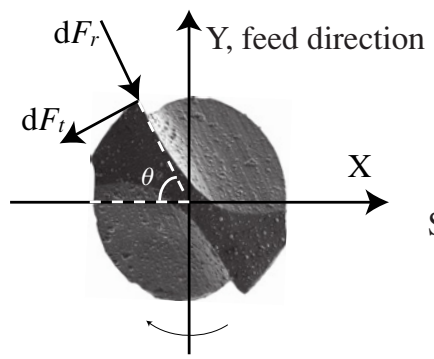

(a)

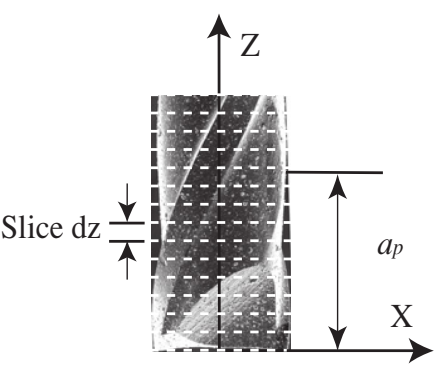

(b)
Figure 3. Illustration of the coordinate system for the force model. The $\mathrm{d} F_{r}$ and $\mathrm{d} F_{t}$ are elemental forces applied on the tool tip; depth of cut $a_{p}$ is divided into pieces ( $\mathrm{d} z$ ) during calculation to take into account tool helix angle.

all the tool flutes that are involved in cutting. Then, the total instantaneous forces on the cutter at immersion $\theta$ and the average forces in one tooth immersion period can be calculated.

The machining parameters used to model the forces are depth of cut $\left(a_{p}\right)$, width of cut $\left(a_{e}\right)$ and feed per tooth $\left(f_{z}\right)$. A number of experiments to calibrate the modelling parameters were carried out. These parameters were then used to validate the measured forces against the predicted forces. Table 1 gives an overview of the validation experiments. The errors between the predicted forces and measured forces in both the $X$ - and $Y$-directions are seen to be less than $11 \%$.

The reason that this conventional force model shows good accuracy for micromilling can be explained from the following aspects. First, this model has taken into account the most significant force components in micromilling: shearing and ploughing. Secondly, as in most of the force models in milling, this model is in nature an empirical model. There are four force coefficients in this model to amend the difference between real cutting forces and modelled forces. Thirdly, this model is used to model average forces in this work, instead of dynamic forces. The relationship between average forces and volume of chip removal is consistent, and not influenced greatly by the process runout. Fourthly, for the given size of the micro cutting tool and applied machining parameters, the micromilling process is shearing dominant.

Due to the interrupted nature of the micromilling process, the tool immersion period can be divided into ploughingdominant and shearing-dominant periods. The micro cutting tools used in this research are $\varnothing 0.5 \mathrm{~mm}$ square endmills. The cutting edge radius of the endmills is measured to be about $2 \mu \mathrm{m}$. The applicable range of feed per tooth is $2-12 \mu \mathrm{m}$. Suppose that the feed per tooth is chosen to be $7 \mu \mathrm{m}$. If the critical value of minimum chip thickness is assumed to be $40 \%$ of the cutting edge radius [11], the ploughing period will be about $7.3 \%$ of the total tool immersion period, and the shearing period $92.7 \%$. Therefore, it can be concluded that the general behaviour of the micromilling process on such a scale is defined by the shearing period.

\subsection{Study of the relationship between machining parameters and the average forces}

The force model established in the previous section is now used to study the influence of the machining parameters on the predicted forces. It should be remembered that the primary interest is in obtaining a valid model for the bending phenomenon in machining of micro-ribs. When the micro feature in question is aligned parallel to the $Y$-direction (with reference to figure 3 ), bending can only be caused by a force acting in the $X$-direction, i.e. normal to the micro-ribs. In view of this, the effect of each machining parameter on the average predicted force $F_{x}$ was studied. Note that the force depends on multiple parameters and its behaviour can be studied by varying only one parameter at a time or two or more parameters simultaneously.

First, the main effect of each machining parameter $\left(f_{z}, a_{p}\right.$ and $a_{e}$ ) on the average force of $F_{x}$ was examined for constant values of the other two parameters. The predicted forces for two different scenarios of up-milling and down-milling are plotted against variations in each parameter in figure 4.

From figure 4, the following aspects can be observed.

- The amplitude of the average force for down-milling is always higher than that for up-milling. This clearly illustrates that up-milling is a preferred strategy for the micromachining of thin features.

- For up-milling the magnitude of the force is observed to increase with width of cut $\left(a_{e}\right)$ and the feed per tooth $\left(f_{z}\right)$. From figures $4(a)$ and $(c)$, the effect of $a_{e}$ is more significant than that of $f_{z}$. This suggests a cautious approach to the choice of $a_{e}$. From figure 4(b), it can be observed that the increase of $a_{p}$ (within a small range) does not increase the average force significantly. This means that a larger value of $a_{p}$ (to a certain extent) can be used to improve the productivity without affecting the workpiece quality. 


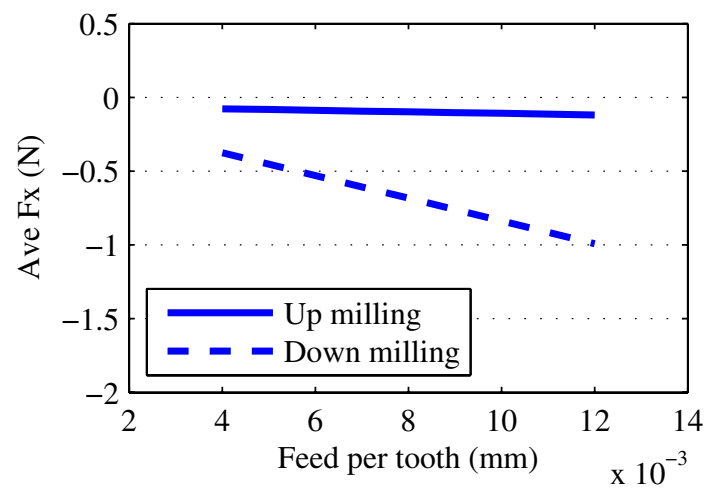

(a)

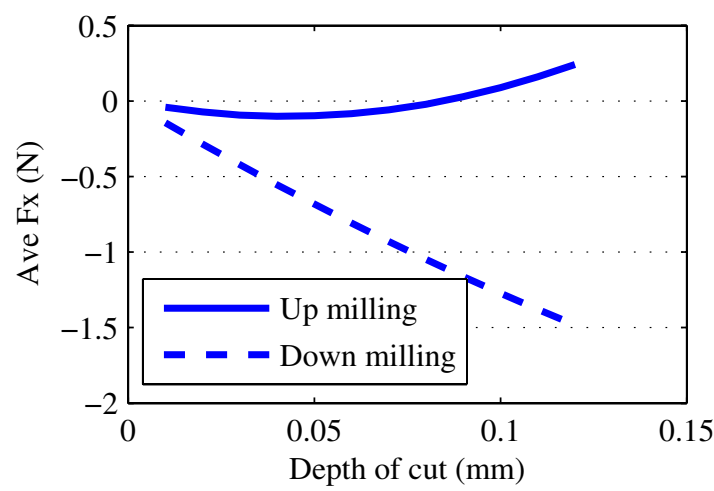

(b)

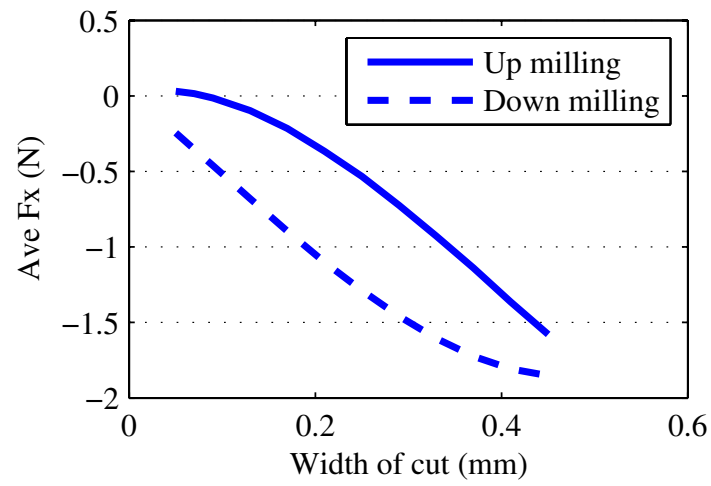

(c)

Figure 4. Modelled main effect of machining parameters on the average force in the direction perpendicular to the ribs: $(a)$ main effect of $f_{z}\left(a_{e} 0.13 \mathrm{~mm}, a_{p} 0.05 \mathrm{~mm}\right),(b)$ main effect of $a_{p}\left(a_{e} 0.13 \mathrm{~mm}, f_{z} 0.008 \mathrm{~mm}\right)$ and $(c)$ main effect of $a_{e}$, ( $\left.f_{z} 0.008 \mathrm{~mm}, a_{p} 0.05 \mathrm{~mm}\right)$.

- For down-milling, the amplitude of average force increases with an increase in all three parameters. Again $a_{e}$ has the most significant effect. Although smaller $a_{e}$ gives lower force for both up- and down-milling, the value of $a_{e}$ cannot be chosen too small. Otherwise, the undesired minimum chip thickness effect will become dominant.

From the preceding discussion, up-milling is preferred over down-milling for micromachining of thin ribs. For the remainder of this paper, results obtained through up-milling only are presented. To further understand the interaction effects between machining parameters, the value of feed per

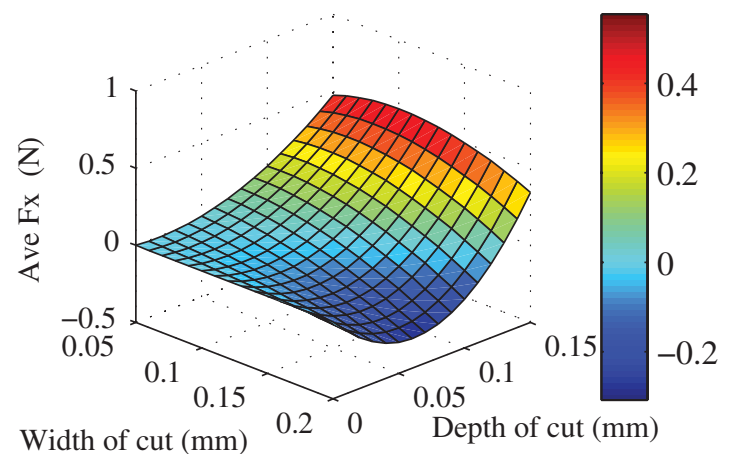

(a)

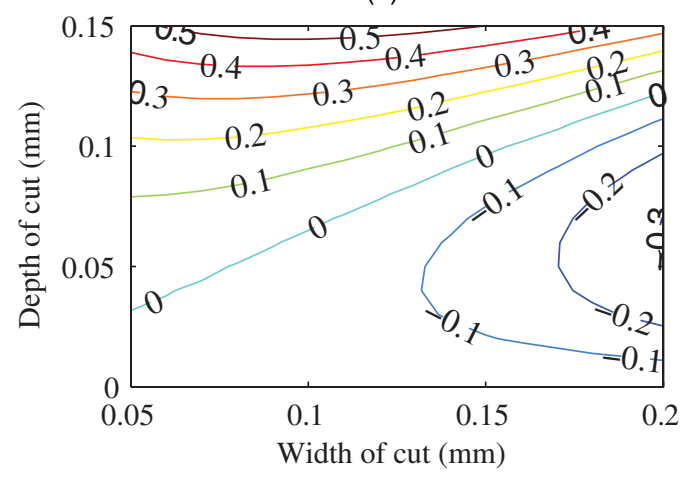

(b)

Figure 5. Effect of $a_{p}$ and $a_{e}$ on the average $F_{x}, f_{z}$ is fixed at $0.007 \mathrm{~mm}$ : (a) surface plot and $(b)$ contour plot.

tooth $\left(f_{z}\right)$ was fixed at $0.007 \mathrm{~mm}$ and the other two parameters were varied simultaneously.

From figure 5, it can be observed that there exists a region where the combination of $a_{e}$ and $a_{p}$ produces a force lower than the predefined level when all the other parameters are fixed. For example, if the desired absolute force level is set to be $0.1 \mathrm{~N}$, different combinations of $a_{e}$ and $a_{p}$ can be found in figure $5(b)$ to fulfil the requirement.

\subsection{Bending of micro endmills}

During machining, not only the thin features, but also the micro endmill will bend under the milling force. The stiffness of the used $\varnothing 0.5 \mathrm{~mm}$ endmill was measured to be about $0.4 \mathrm{~N} \mu \mathrm{m}^{-1}$. Suppose that the stiffness of the machine tool (including the tool holder) is five times higher than that of the cutting tool and the average $F_{x}$ is $0.1 \mathrm{~N}$, then the calculated deflection of the cutting tool will be smaller than $0.5 \mu \mathrm{m}$, which is acceptable.

\section{Study of tool paths}

\subsection{Conventional tool path and proposal for improvement}

The conventional tool path that is commonly used in micromilling of thin features is best explained using figure 6(a). It illustrates the principle of constant level Z. A simple thin-rib serves as sample geometry for the thin feature. The machining sequence is indicated in figure 6(a). By using this tool path, it is clear that at the even sequences, there is no support to the rib from the other side, which will result in 


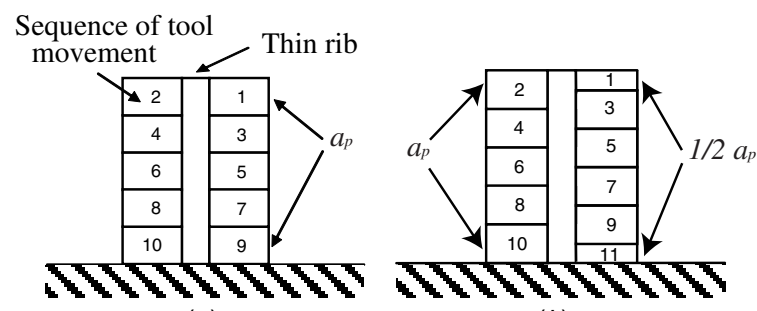

(a)

(b)

Figure 6. Illustration of $(a)$ the conventional and $(b)$ the improved tool path. Up-milling is assumed as tool moves into the paper at odd sequence and out of the paper at even sequence.

bending or damage of the rib under the milling force. This works well when the bending of the rib is not crucial (for example in thick features). However, when the width of the rib is small enough and the designed AR is high, its limitations will become critical for the success of the machining. The lack of support at the even numbered sequence for this tool path has been identified as a fundamental problem that needs to be addressed.

To overcome this problem, we propose an improved tool path, shown in figure $6(b)$. For the new tool path, the cutting tool only removes a portion of depth of cut (that is, a certain percentage of $a_{p}$ ) in sequence 1 . When the tool moves to the other side to complete sequence 2 , it can machine the complete depth of cut in one shot. During this sequence, the rib is always supported by the partial material on the other side. As a consequence, after an even number of tool sequences, the surfaces on both sides of the rib are not at the same level. The advantage of the improved tool path is that there is structural support to the rib during machining.

\subsection{Comparison of the two types of paths}

The effectiveness of the two types of tool paths can be compared by means of FEM models of a rib assumed to be $25 \mu \mathrm{m}$ thick and $500 \mu \mathrm{m}$ high. The workpiece material is Böhler M261 which is the same material used for the force model. Its Young's modulus is $210 \mathrm{GPa}$, Poisson's ratio = 0.29 and density $=0.0078 \mathrm{~g} \mathrm{~mm}^{-3}$. The FEM analysis is done using COSMOSWorks [18]. The force magnitude is assumed to be $1 \mathrm{~N}$ for both a full $a_{p}(0.1 \mathrm{~mm})$ and half $a_{p}$ according to the results of force modelling. The direction of the force is normal to the rib and pushes the rib away. The location of the force is near the side edge of the rib, which represents the worst-case scenario that results in maximum bending of the rib. Analysis on each sequence of tool movements for both tool paths was performed. The results are shown in figure 7 and table 2; only the maximum deflection of the rib is recorded.

For the conventional tool path, when there is material support from the other side, the deflection of the rib is small $(<1 \mu \mathrm{m})$. However, when there is no support from the other side, the deflection of the rib is relatively large and increases rapidly when the cutting (force) approaches the bottom of the rib.

For the improved tool path, the increase in deflection is more gradual, and there is no clear difference among the

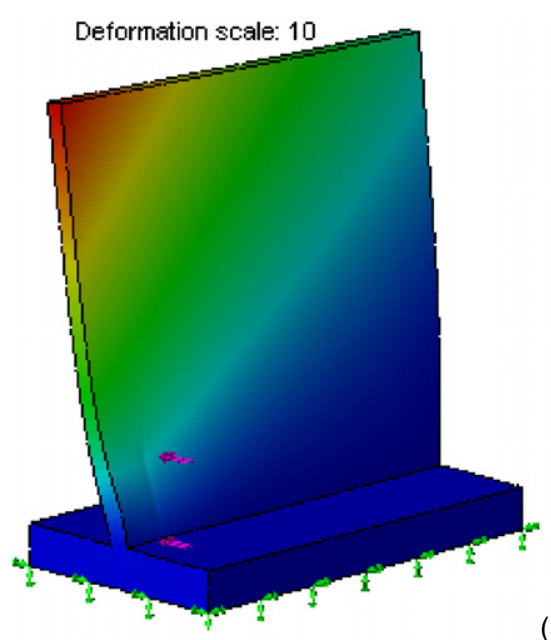

URES (m)

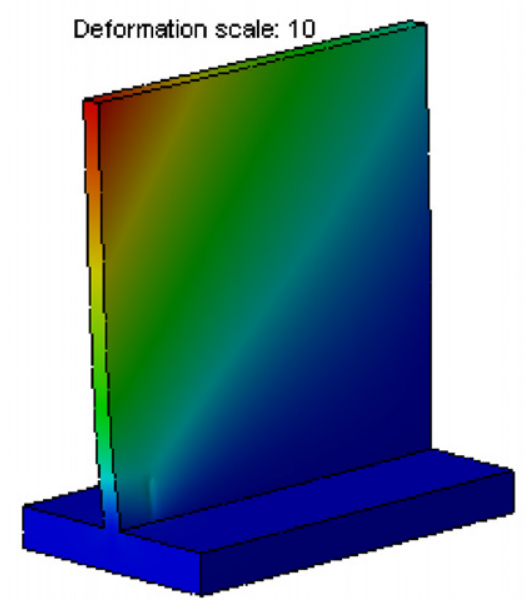

(a)

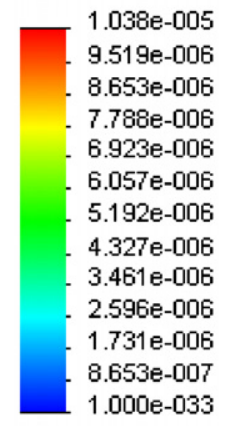

URES (m)

$3.455 \mathrm{e}-006$

$3.167 \mathrm{e}-006$

$2.879 \mathrm{e}-006$

$2.591 \mathrm{e}-006$

$2.303 \mathrm{e}-006$

$2.015 \mathrm{e}-006$

$1.727 \mathrm{e}-006$

1.440e-006

$1.152 \mathrm{e}-006$

$8.637 \mathrm{e}-007$

$5.758 \mathrm{e}-007$

$2.879 \mathrm{e}-007$

$1.000 \mathrm{e}-033$

(b)

Figure 7. Deflection of the rib at the last tool movement sequence, both for $(a)$ the conventional tool path and $(b)$ the improved tool path.

odd and the even sequences. The rib deflection at the last movement (sequence 11) is $3.5 \mu \mathrm{m}$, about three times lower than when the conventional tool path is used.

\section{Dynamic behaviour of the thin ribs}

In order to understand the interactions between the cutting forces and the dynamics of thin ribs, a modal analysis was performed. The stiffness and natural frequency of a thin beam depend on its dimensions (length, width and height) and, when scaled down by a factor of 10 in each dimension, stiffness decreases, and natural frequency increases, by a factor of 10. Micro-ribs are therefore very flexible with high resonance frequency.

A simulation, for a rib of $500 \times 25 \times 500 \mu \mathrm{m}(\mathrm{L} \times$

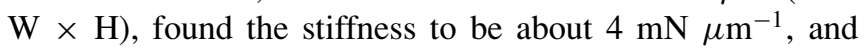
natural frequency to be about $86 \mathrm{kHz}$; for a rib of $500 \times$

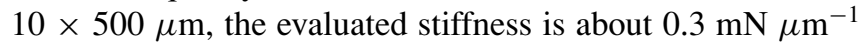
and its natural frequency is about $35 \mathrm{kHz}$. This analysis again shows that the process force has to be controlled well and it is essential to give support to micro features during machining.

In this research, micro-ribs were machined at a spindle speed of $30000 \mathrm{rpm}$. Since the micro endmill has two flutes, 
Table 2. Maximum deflections of the ribs for the two tool paths $(\mu \mathrm{m})$.

\begin{tabular}{llllllllllll}
\hline Sequence & 1 & 2 & 3 & 4 & 5 & 6 & 7 & 8 & 9 & 10 & 11 \\
\hline Conventional path & 0.6 & 4.5 & 0.5 & 6.9 & 0.4 & 8.2 & 0.3 & 9.3 & 0.2 & 10.4 & - \\
Improved path & 0.6 & 1.3 & 1.6 & 1.9 & 2.0 & 2.1 & 2.2 & 2.3 & 2.3 & 2.4 & 3.5 \\
\hline
\end{tabular}

Table 3. List of designed values, cutting conditions and results of machined ribs.

\begin{tabular}{|c|c|c|c|c|c|c|c|c|}
\hline \multicolumn{2}{|c|}{ Designed value } & \multicolumn{4}{|c|}{ Cutting conditions } & \multicolumn{3}{|c|}{ Results } \\
\hline Width $(\mu \mathrm{m})$ & Height $(\mu \mathrm{m})$ & $a_{p}(\mu \mathrm{m})$ & $a_{e}(\mu \mathrm{m})$ & Tool path & Up/down milling & Status & Width $^{\mathrm{b}}(\mu \mathrm{m})$ & AR \\
\hline 50 & 500 & 100 & 100 & Con., new & Up & Success & 61 & 8 \\
\hline 30 & 500 & 100 & 100,200 & Con., new & Up, down & Success & 41 & 12 \\
\hline 20 & 500 & 100 & 100,200 & Con., new & Up, down & Success & 30 & 17 \\
\hline 15 & 500 & 50 & 80 & Con., new & Up & Success & 23 & 22 \\
\hline 12 & 500 & 50 & 80 & Con., new & Up & Success & 14 & 36 \\
\hline 10 & 500 & 50 & 80 & Con. & $\mathrm{Up}$ & Success & 15 & 33 \\
\hline 10 & 500 & 50 & 80 & New & $\mathrm{Up}$ & Success & 14 & 36 \\
\hline 8 & 500 & 100 & 80 & Con. & Up & Failure & - & - \\
\hline 8 & 500 & 100 & 80 & New & Up & Success & 10 & 50 \\
\hline 6 & 500 & 100 & 80 & Con. & Up & Failure & - & - \\
\hline 6 & 500 & 100 & 80 & New & Up & Success ${ }^{\mathrm{a}}$ & 8 & 63 \\
\hline 16 & 800 & 40,80 & $70,80,90$ & New & Up & Success & 21 & 38 \\
\hline 12 & 800 & 40,80 & $70,80,90$ & New & Up & Success & 15 & 53 \\
\hline
\end{tabular}

${ }^{a}$ Successful in strategies, but the quality of the ribs is not good.

$\mathrm{b}$ The error in the rib width is due to the uncertainty in measurement of the tool dynamic diameter.

${ }^{c}$ All ribs have the same length, $2 \mathrm{~mm}$.

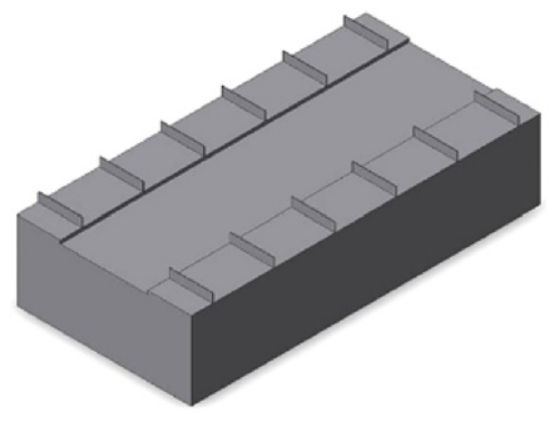

Figure 8. CAD drawing of the test workpiece with 12 thin ribs.

the cutting frequency is $1 \mathrm{kHz}$, which is significantly lower than the natural frequency of the ribs. Therefore, it can be concluded that the rib is unlikely to be excited by the cutting forces during micromilling. However, there is a trend in research to use higher speed spindles in micromilling. The relationship between the natural frequency of micro features and the cutting frequency should be checked carefully when a high spindle speed is used.

\section{Machining of micro-ribs}

In this section, experimental results are presented that validate the claims pertaining to the force model and the novel tool path. On the $20 \times 10 \mathrm{~mm}$ surface of the workpiece (Böhler M261), 12 ribs were machined, as shown in figure 8.

The machining of the ribs comprises three operations: namely roughing, re-roughing and finishing. During the roughing and re-roughing operations, bigger tools $(\varnothing 3 \mathrm{~mm})$ were used to remove bulk material and leave enough allowance for the next operation. Finishing is the operation that machines the ribs to their final shapes. The same type of commercial $\varnothing$ $0.5 \mathrm{~mm}$ endmill was chosen, as that used in the force model development. The machining parameters and tool paths were chosen according to theoretical analysis.

The 12 ribs on one workpiece were machined with different combinations of tool paths and machining parameters, to get a statistically reliable result, as shown in table 3 . The spindle speed was fixed at $30000 \mathrm{rpm}$, which gave a relatively smaller dynamic runout according to preliminary tests. The feed rate was fixed at $420 \mathrm{~mm} \mathrm{~min}^{-1}$. The machining time for one rib in the finishing operation was $<30$ s. Five workpieces (altogether 60 ribs) were machined.

\section{Results and analysis}

The machined ribs were observed and measured by scanning electron microscopy and white light interferometry.

\subsection{General observations}

In summary, the machining of micro-ribs was successful; all the planned micro-ribs could be realized under the chosen cutting conditions. No manual intervention was needed during machining. Ribs machined under the same cutting conditions showed similar quality, meaning that the repeatability of the process was good.

The rib in figure 9 has an AR of 54 (width $\sim 15 \mu \mathrm{m}$, height $\sim 800 \mu \mathrm{m})$. It is seen that the quality of this rib is good both in terms of its shape and the surface quality. The rib is straight seen from the side view in figure $9(a)$ and the top view in figure $9(b)$. Figure $9(d)$ shows a higher magnification view 


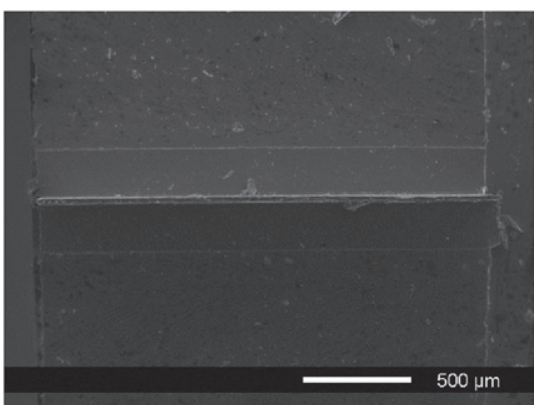

(a)

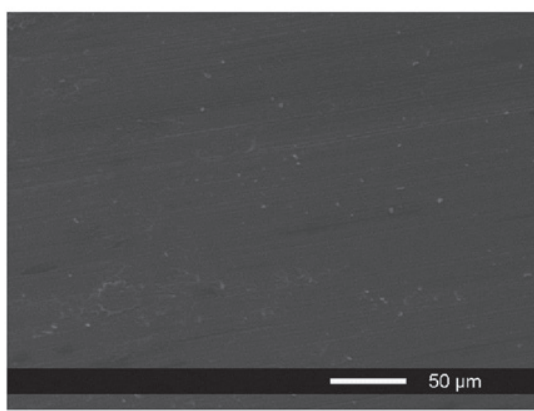

(c)

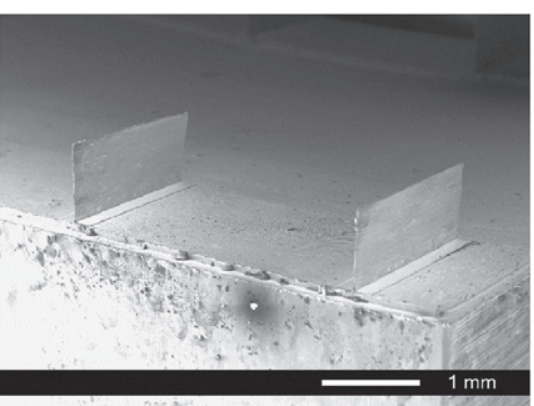

(b)

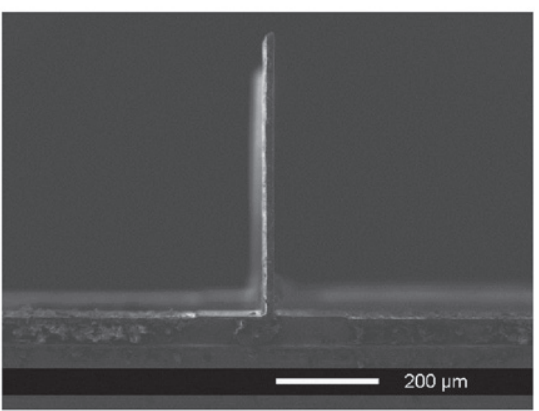

$(d)$

Figure 9. The rib with an AR of 54 (width $15 \mu \mathrm{m}$, height $800 \mu \mathrm{m}$ ).

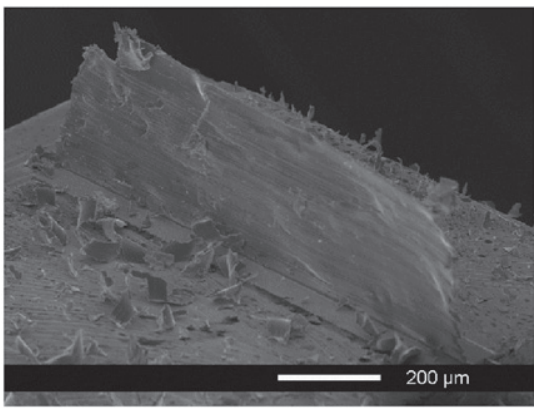

(a)

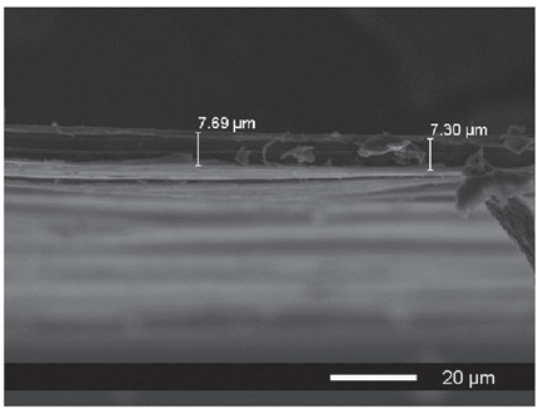

(b)

Figure 10. The rib with an AR of 63 (width about $8 \mu \mathrm{m}$, height $500 \mu \mathrm{m}$ ): (a) 3D view and $(b)$ measurement of the rib width.

of the machined surface with a surface roughness of $0.3 \mu \mathrm{m}$ $(R a)$.

The highest $\mathrm{AR}$ achieved in experiments was about 63 (width $\sim 8 \mu \mathrm{m}$, height $\sim 500 \mu \mathrm{m}$ ). The machined ribs are shown in figure 10. It can be seen that the overall shape of this rib was acceptable and the designed height was achieved. However, the quality of the rib is not good. The body of the rib can be seen to be twisted. This can be attributed to insufficient strength in the thin rib to withstand forces along its longitudinal direction $\left(F_{y}\right)$. This indicates that for thick ribs, plastic deformation is local (chip formation); when the rib is too thin, plastic deformation will become global. Therefore, for machining ribs of such small scales, both the forces that are normal to the direction of the rib and those that are parallel become prominent.

The microstructure of the workpiece material also influences the surface quality. Future research will be directed to gain greater insights into this aspect.
In this research, the achievable AR was limited by the maximum underneck length of the micro cutting tool, which was $0.8 \mathrm{~mm}$. Since the quality of the rib was very good under the chosen cutting conditions, it is believed that micro-ribs with even higher ARs can be machined successfully if tools with longer underneck lengths become available.

\subsection{Evaluation of tool paths}

Experimentally, it has been observed that the improved tool path proposed in this paper outperformed the conventional tool path, especially when the rib width was $<10 \mu \mathrm{m}$. When the rib width is within this range, using the conventional tool path leads to poor quality and an eventual fracture of the rib. The ribs machined by using the improved tool path could always be machined successfully under the conditions tested.

Figure 11 is a highly magnified view of the sidewalls of the ribs machined by both types of tool paths. The rib machined by the conventional tool path, figure 11(a), shows a saw-toothed 


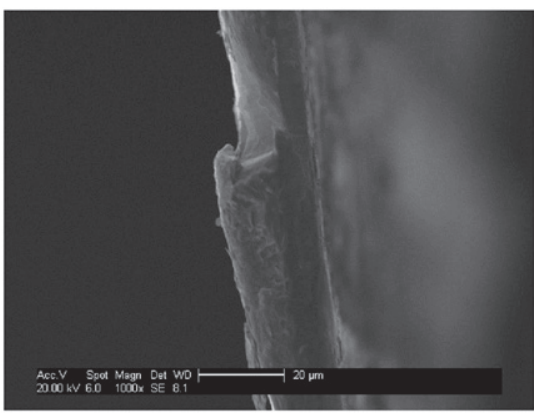

(a)

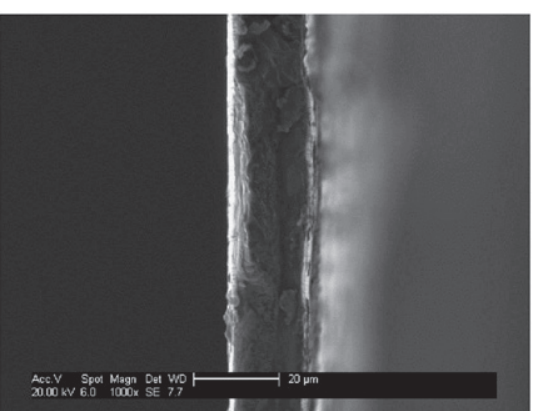

(b)

Figure 11. Side views of the ribs machined by the two tool paths: $(a)$ by the conventional tool path and $(b)$ by the improved tool path. The rib width is about $14 \mu \mathrm{m}$

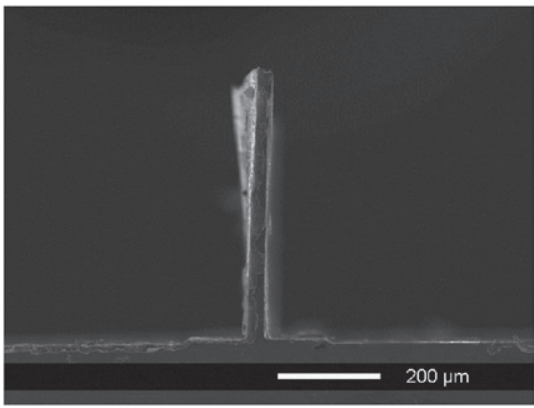

(a)

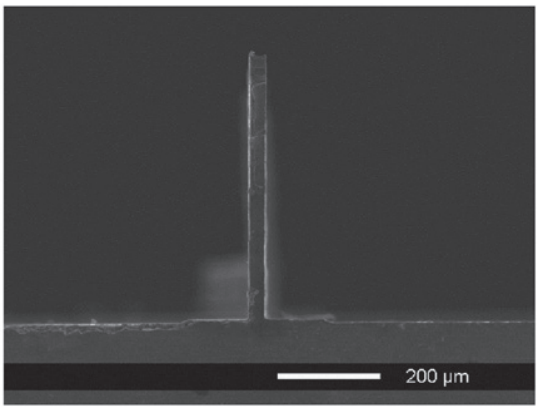

(b)

Figure 12. Side views of ribs (width $30 \mu \mathrm{m}$, height $500 \mu \mathrm{m}$ ) machined by down-milling and up-milling: $(a)$ by down-milling and $(b)$ by up-milling.

Table 4. Comparison of measured and predicted forces.

\begin{tabular}{lccllll}
\hline & \multicolumn{3}{c}{ Cutting conditions } & & \multicolumn{2}{c}{ Ave $\left|F_{x}\right|(\mathrm{N})$} \\
\cline { 2 - 3 } $\begin{array}{l}\text { Rib width } \\
(\mu \mathrm{m})\end{array}$ & $a_{p}(\mu \mathrm{m})$ & $a_{e}(\mu \mathrm{m})$ & $\begin{array}{l}\text { Up/down } \\
\text { milling }\end{array}$ & & Measured & Predicted \\
\hline 30 & 100 & 100 & Up & 0.15 & 0.15 \\
30 & 100 & 100 & Down & & 0.84 & 0.92 \\
19 & 80 & 70 & Up & & 0.09 & 0.09 \\
15 & 40 & 80 & Up & 0.05 & 0.02 \\
\hline
\end{tabular}

feature on the one side of the rib. The distance between two sawteeth is $50 \mu \mathrm{m}$, which equals the applied depth of cut $\left(a_{p}\right)$. This side was machined on the even sequences of the tool movements; there was no support from the other side during machining. The rib machined by the improved tool path, figure $11(b)$, is clearly devoid of such issues.

\subsection{Cutting conditions}

The measured average of the cutting forces was compared with the theoretically predicted values. They showed good agreement, as shown in table 4 .

When machining ribs with a width of $30 \mu \mathrm{m}$, both up- and down-milling were used. The measured force in down-milling was $0.84 \mathrm{~N}$, which is about 5.6 times higher than that in upmilling. The force model used also predicted the same levels of increase. The relative thickness of the rib prevented its fracture under the influence of high amplitude forces. However, the quality of the rib has deteriorated remarkably in comparison to that machined in up-milling, as shown in figure 12.

\section{Conclusions}

This paper discusses the challenges in micromilling of thin features with high aspect ratios. In particular, the effects of process control have been considered, especially by choosing suitable machining parameters, the machining strategy and tool paths for the micromilling of micro-ribs. A fundamental understanding of the cutting forces involved in micromilling was obtained and the relationship to various machining parameters and milling strategy. A well-known macro scale model from the literature was used to obtain predictions of the average cutting forces in micromilling. This model was found to be a fairly accurate representation of the measured cutting forces from the experiments conducted. This is probably because, under the given experimental conditions, the micromilling process is still a shearing-dominant process. It was observed that the structural properties of micro-ribs are affected by the scaling effects. The low stiffness and higher natural frequencies indicate that the cutting forces do not excite the resonant modes for lower spindle speeds considered in this paper. It has been noted that up-milling results in significantly lower amplitudes of the cutting forces than in down-milling. In order to circumvent the problems that arise due to the lack 
of support during micromachining of thin ribs, an improved tool path for processing has been proposed. The advantages of the proposed strategies were examined using FEM analysis and verified in experiments.

For further research, it will be interesting to study the surface texture of thin ribs which is related to the dynamics of micromilling. The influence of the process runout on dimensional accuracy is another aspect which demands further investigation.

\section{Acknowledgments}

This work is being supported by the Innovation Research Program (IOP) of the Dutch Government, Launch Micro Project (FP6-NMP) of the European Community, reference no 11795 and EPSRC Grand Challenge project '3DMintegration'. The authors gratefully acknowledge Mr DJ IJlst, Mr J Hedge and Dr T Jin for their helpful assistance during experiments.

\section{References}

[1] Bang Y B, Lee K M and Oh S 2005 5-axis micro milling machine for machining micro parts Int. J. Adv. Manuf. Technol. 25 888-94

[2] Gietzelt T, Eichhorn L and Schubert K 2005 Micromechanical structuring of polymers, metals, and ceramics Proc. 1st Int. Conf. on Multi-Material Micro Manufacture (Karlruhe, Germany) pp 329-32

[3] Masuzawa T 2000 State of the art of micromachining Ann CIRP 49 473-88

[4] Popov K, Dimov S, Pham D T and Ivanov A 2006 Micromilling strategies for machining thin features Proc. Inst. Mech. Part C: J. Mech. Eng. Sci. 1677-84

[5] Takács M, Verö B and Mészáros I 2003 Micromilling of metallic materials J. Mater. Process. Technol. 138 152-5
[6] Takeuchi Y, Suzukawa H, Kawai T and Sakaida Y 2006 Creation of ultra-precision microstructures with high aspect ratios Ann. CIRP 55 107-10

[7] Uhlmann E and Schauer K 2005 Dynamic load and strain analysis for the optimization of micro end mills Ann. CIRP $\mathbf{5 4} 75-8$

[8] Je T, Lee J, Choi D, Lee E, Shin B and Whang K 2004 A study of the micro pole structure fabrication and application technology by micro end-milling processes Key Eng. Mater. 257-8 453-8

[9] Uriarte L, Ivanov A, Oosterling J A J, Staemmler L, Tang P T and Allen D M 2005 A comparison between microfabrication technologies for metal tooling Proc. 1st Int. Conf. on Multi-Material Micro Manufacture (Karlruhe, Germany) pp 351-4

[10] Kim C J, Mayor J R and Ni J 2004 A static model of chip formation in microscale milling J. Manuf. Sci. Eng. $126710-8$

[11] Liu X, DeVor R E, Kapoor S G and Ehmann K F 2004 The mechanics of machining at the microscale: assessment of the current state of the science J. Manuf. Sci. Eng. $126666-78$

[12] Vogler M P, DeVor R E and Kapoor S G 2004 On the modeling and analysis of machining performance in micro-endmilling: part I. Surface generation J. Manuf. Sci. Eng. 126 685-94

[13] Ikawa N, Shimada S and Tanaka H 1992 Minimum thickness of cut in micromachining Nanotechnology 3 6-9

[14] Özel T and Liu X 2008 Modeling based micro-milling process planning for machining mold cavities CIRP 3rd Int. Conf. High Performance Cutting (Dublin, Ireland) pp 805-17

[15] Dimov S, Pham D T, Ivanov A and Popov K 2005 Micro milling of thin features 1st Int. Conf. on Multi-Material Micro Manufacture (Karlsruhe) pp 363-6

[16] Rahman M, Kumar A S and Prakash J R S 2001 Micro milling of pure copper J. Mater. Process. Technol. $11639-43$

[17] Altintas Y 2000 Manufacturing Automation: Metal Cutting Mechanics, Machine Tool Vibrations, and CNC Design (Cambridge: Cambridge University Press)

[18] Solidworks Corp. www.solidworks.com 